\title{
High-speed pulsed thermography of thin metallic coatings
}

\author{
by $U$. Netzelmann and $G$. Walle
}

Fraunhofer-Institute for Nondestructive Testing, University, Bldg. 37, 66123 Saarbrücken, Germany

\begin{abstract}
A high-speed pulsed video thermographic system based on an infrared array camera was set up. For excitation, a flash lamp with controllable pulse duration was used. Metallic MCrAlY coatings on Nibase alloy with thicknesses in the range of 37 to 130 microns were studied. Delaminations at the interface of a $310 \mu \mathrm{m}$ thick copper layer on aluminium nitride ceramic could be observed. The thermal decay curves were modelled considering the measured the temporal profile of the excitation light. The results were verified by high-frequency ultrasound measurements at 50 to $80 \mathrm{MHz}$.
\end{abstract}

\section{Introduction}

Metallic coatings play an important role for many industrial components. For example, on blades of modern aircraft gas turbines coatings consisting of Pt-aluminides, MCrAlY and gamma-Ti-aluminides are used as protection against hot gas oxidation or corrosion. Such coatings have a typical thickness of 30 to 150 microns. There is high commercial interest in non destructive control of coating thickness after manufacturing and of the residual coating thickness during maintenance cycles. Further tasks are detection of delaminations and coating composition. Large areas on turbine blades have to be inspected. Other important applications are copper layers on ceramic substrates, that act as heat sinks for electronic components.

\section{Experimental technique}

Pulsed thermography is a technique suitable for fast inspection of large surfaces. Due to the high thermal conductivity of metallic coatings, typical characteristic diffusion times are of the order of 0.1 to $3 \mathrm{~ms}$, which is much less than the time resolution of conventional infrared scanner cameras. Infrared array cameras give access to fast thermal phenomena [1]. Here, an infrared array camera for the 3-5 $\mu \mathrm{m}$ wavelength range (AIM, Heilbronn, Germany) with a maximum frame rate of 1100 frames per second and 14 bit dynamic range was used. The temperature resolution i was $50 \mathrm{mK}$. A large built-in frame memory allows the recording of a thermal decay for a time of a few seconds. The frames can be edited either directly in the camera or in a computer connected to the camera via a fast digital interface. A software running under Windows NTrM is available for user-friendly acquisition and evaluation of frame sequences. The test equipment is designed to be transportable (Fig. 1).

When a conventional high-power flash lamp (pulse half-width 3 to $5 \mathrm{~ms}$ ) is used to excite the thermal diffusion process, the contrast due to coating thickness appears within the long exponential decay of the lamp discharge and may therefore be superimposed by spurious reflections of the long-wavelength components of the flash radiation.

We use a special thyristor switched flash-lamp which allows the very rapid cutting of the discharge. A typical pulse shape $H(t)$ as measured by a fast photodiode connected to a transient digitizer is shown in Fig. 2. The pulse duration can be varied from about $3 \mathrm{~ms}$ down to some ten microseconds.

\subsection{MCrAlY coatings}

As a first example, MCrAlY coatings produced by physical vapour deposition were studied. Samples with different coating thickness (37 to 130 microns) on an common Ni-base 
alloy substrate were available. No additional coating for homogenisation of the infrared emissivity was used. Fig. 3a shows the IR image of the sample before firing the heating flash. At very short time after excitation, the roughness of the coating surface produces a marked contrast (Fig. 3b). Brighter grey steps represent higher temperature. The temperature contrast due to different thickness is clearly resolved within 4 to $8 \mathrm{~ms}$ after excitation (Fig. 3c). About $20 \mathrm{~ms}$ after excitation, the contrast almost vanishes (Fig. 3d). This is in accordance with the result obtained with a conventional pulsed video thermographic system (25 frames/second), which was not able to resolve the thickness contrast of the sample.

The results of thermographic measurement were verified by a high-frequency ultrasound B-scan performed through the substrate side of the sample. Ultrasound measurements from the coating side are usually difficult due to the roughness of the coating.

\subsection{Modelling}

For quantitative modelling of the fast thermal decay curves, one can use the well known one-dimensional solution for the thermal decay in an opaque coating excited by a delta pulse [2]. The surface temperature $\vartheta_{\delta}(0, t)$ is given by:

$$
\vartheta_{\delta}(0, t)=\frac{I_{0}}{2 \sqrt{\pi} \varepsilon_{1} \sqrt{t}}\left(1+2 \sum_{j=1}^{\infty}\left(\frac{\varepsilon_{1}-\varepsilon_{2}}{\varepsilon_{1}+\varepsilon_{2}}\right)^{j} e^{-\frac{j^{2} d^{2}}{\alpha_{1^{\prime}}}}\right)
$$

Here, $\varepsilon_{1}$ and $\varepsilon_{2}$ are the effusivity of the coating and the substrate, respectively, $d$ is the sample thickness, $\alpha_{1}$ the thermal diffusivity of the coating and $l_{0}$ the deposited energy density. The surface temperature is then obtained by a convolution with the measured excitation flash pulse shape $H(t)$ :

$$
\vartheta(0, t)=\int_{0}^{t} H(\tau) \vartheta_{\delta}(t-\tau) d \tau
$$

Fig. 4 shows the result of a calculation modelling the experimental situation of the experiment above. A thermal diffusivity of $\alpha_{1}=8 \cdot 10^{-6} \mathrm{~m}^{2} / \mathrm{s}$ for the coating and effusivities of $\varepsilon_{1}=4000 \mathrm{Ws}^{1 / 2} / \mathrm{Km}^{2}$ and of $\varepsilon_{2}=6100 \mathrm{Ws}^{1 / 2} / \mathrm{Km}^{2}$ for coating and substrate were assumed.

For $t<0.25 \mathrm{~ms}$ all curves are coincident. Then, still during the excitation pulse with a length of $580 \mu \mathrm{s}$, contrast for the thinnest layer occurs (brighter grey steps correspond to higher temperature). Good contrast between the areas with different coating thickness exists only for times less than $10 \mathrm{~ms}$. The result is in good agreement with the experimental findings described above.

\subsection{Copper coated aluminium nitride}

Another problem that requires high time resolution for active thermography is testing of copper coated aluminium nitride serving as a substrate for electronic components. Here, good thermal coupling between copper and the ceramic is essential, as the ceramic (thermal conductivity $175 \mathrm{~W} /(\mathrm{m} \cdot \mathrm{K})$ ) acts as heat sink. A sample with a size of $70 \mathrm{~mm} \times 70 \mathrm{~mm}$ consisting of a layer of $310 \mu \mathrm{m}$ of copper on a $1 \mathrm{~mm}$ substrate of AIN was studied. As the available flash power was limited, for this sample a thin layer of black paint was applied to increase light absorption and infrared emission. Fig. 5 shows the thermal response 10ms after flash (flash duration $2.8 \mathrm{~ms}$ ). On the top and the bottom side, large delaminated areas appear in bright contrast.

The thermographic results were verified by a high-frequency ultrasound C-scan measurement using a $50 \mathrm{MHz}$ focusing transducer in the pulse-echo mode. The sample was scanned from the ceramic side (Fig. 5). The bright grey steps represent a strong interface 


\section{http://dx.doi.org/10.21611/qirt.1998.011}

echo, indicating delaminated areas. The lateral resolution in the C-scan is better than that of the thermographic image. There is a good agreement between the structures found.

\section{Conclusion}

The high acquisition speed of infrared array cameras with frame rates of $1 \mathrm{kHz}$ or more allows one to detect thickness variations and delaminations in thin metallic coatings inaccessible to slow scanner cameras. Short excitation pulses with fast shut-off behaviour have to be used for excitation. Contrast may occur even during the excitation pulse. For quantitative calculation of the early contrast, the pulse shape of the heating pulse has to be taken into consideration. The technique has the potential for fast on-line testing of coatings on turbine blades.

\section{REFERENCES}

[1] WANG (Y.), TELENKOV (S.), WU (Z.), FAVRO (L. D.), KUO (P. K.), THOMAS (R. L.), and VAN OENE (H.) - Rev. Progr. QNDE 15, 1996, p. 1447-1453.

[2] ALMOND (D. P.) and PATEL (P. M.) - Photothermal Science and Techniques. London, Chapman \& Hall, 1996, p. 108.

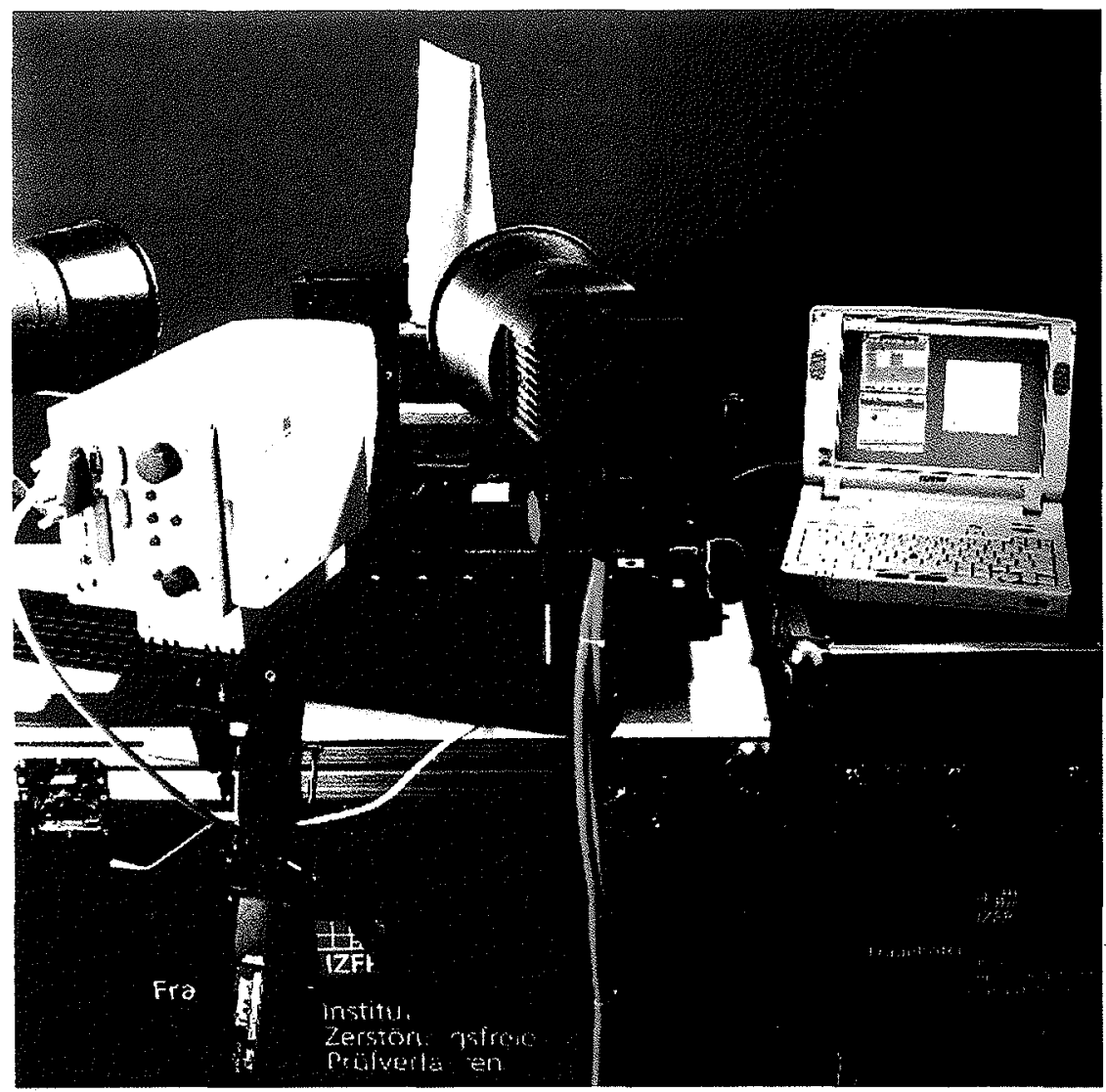

Fig. 1. View of the transportable experimental setup 
http://dx.doi.org/10.21611/qirt.1998.011

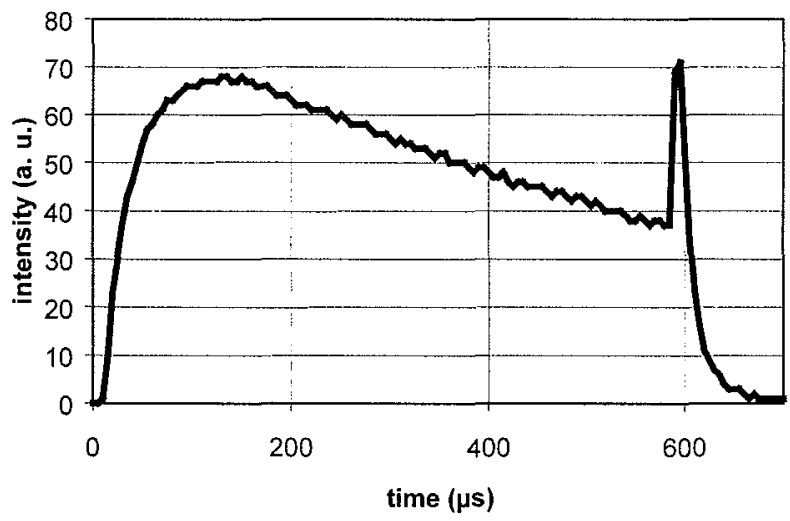

Fig. 2. Typical profile of the flash intensity as a function of time for the thyristorswitched flash lamp employed for high-speed thermography

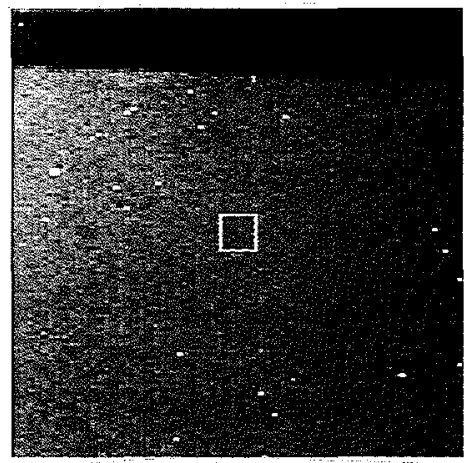

a)

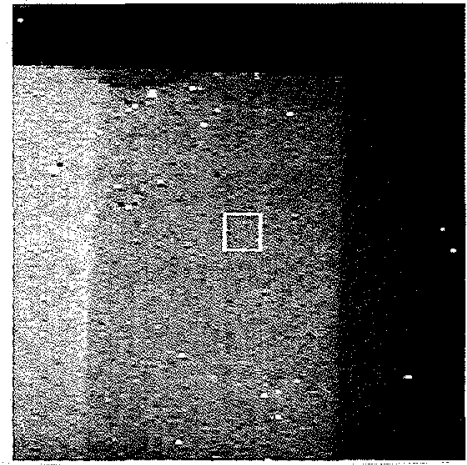

c)

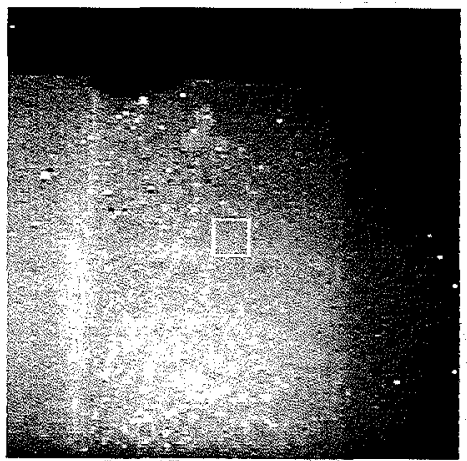

b)

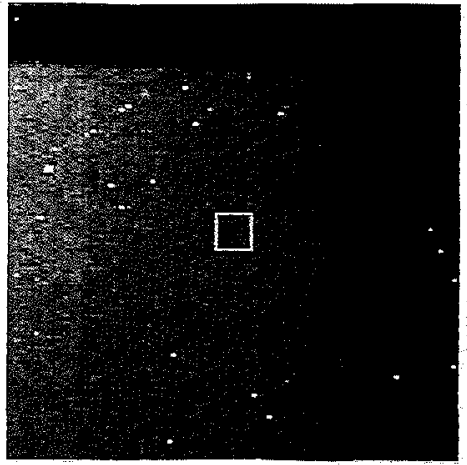

d)

Fig. 3. Pulsed video thermography of MCrAlY coatings of different thickness on a Nibase alloy. a): Image before heating pulse, b): 1-2 $\mathrm{ms}$ after firing the heating pulse, c):

$1.8 \mathrm{~ms}$ after frame b) and d): $18 \mathrm{~ms}$ after frame b) (image area $40 \mathrm{~mm} \times \mathbf{4 0} \mathrm{mm}$ ). The coating thickness is $116 \mu \mathrm{m}$ on the left side, $90 \mu \mathrm{m}$ in the centre and $37 \mu \mathrm{m}$ on the right side 
http://dx.doi.org/10.21611/qirt.1998.011

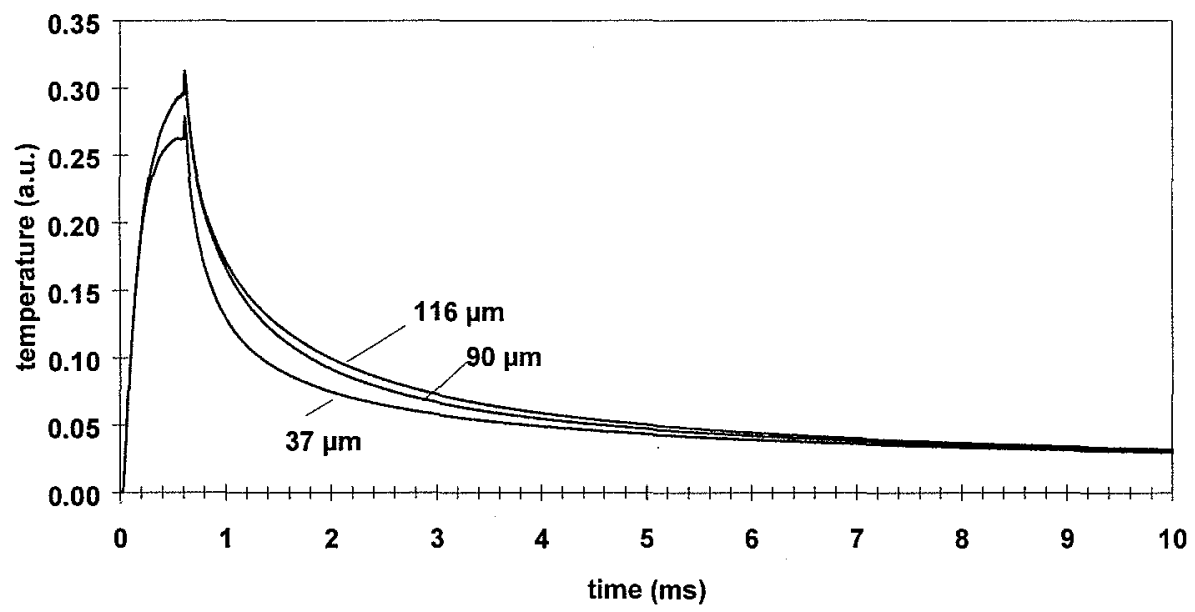

Fig. 4. Calculated thermal contrast curves during flash illumination ( $t<0.6 \mathrm{~ms})$ and after the flash for three coating thicknesses
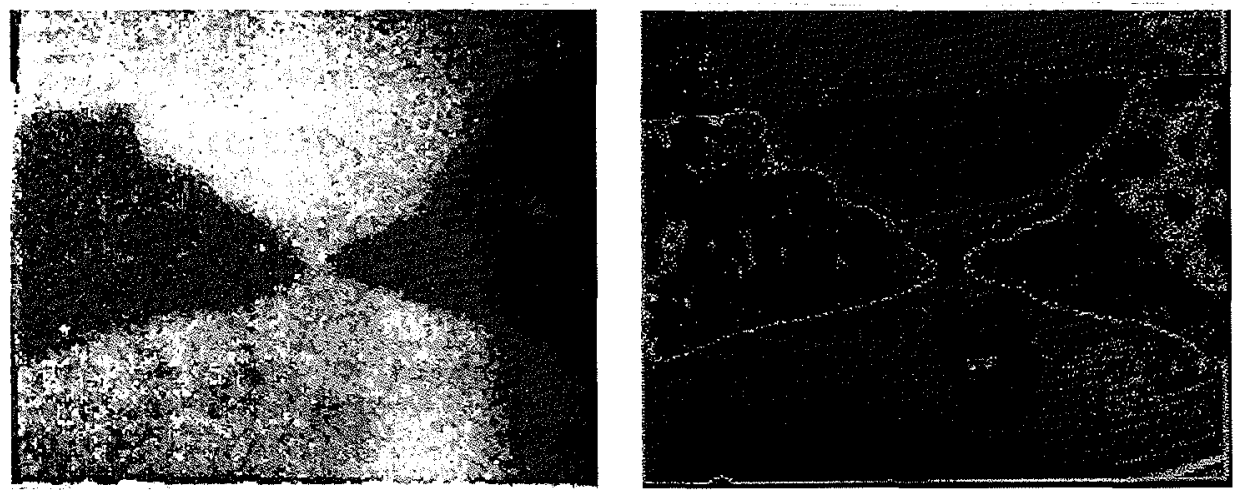

Fig. 5. Left: Pulsed video thermography of a copper layer on ceramic, measured $10 \mathrm{~ms}$ after beginning of flash excitation. Right: High-frequency ultrasound ( $50 \mathrm{MHz}) \mathrm{C}$-scan of the same sample. Image size $60 \mathrm{~mm} \times 70 \mathrm{~mm}$. 